\title{
O RETROCESSO CONSTITUCIONAL E OS DIREITOS REPRODUTIVOS: O CERCEAMENTO DA PARTICIPAÇÃO POLÍTICA DA MULHER POR VIAS CONSTITUCIONAIS
}

\author{
Constitutional retrocession and reproductive rights: the curtainling women's political \\ participation through constitutional means
}

Júlia Carolina Costa Lima

\begin{abstract}
Marina Bonatto
Resumo: O objetivo do presente trabalho é discorrer a respeito das teorias democráticas, bem como sua associação ao constitucionalismo, a fim de demonstrar como a democracia - com especial enfoque na democracia brasileira - apresenta uma queda qualitativa que se dá, exponencialmente, por meios democráticos e constitucionais. Para tanto, primeiramente, pretende-se apresentar brevemente o conceito de democracia e sua necessária associação com os direitos fundamentais apenas para concluir que o modelo democrático adotado no Brasil é insuficiente para efetivar em termos práticos as promessas da constituição programática. Em sequência, intenta-se demonstrar as maneiras de ofensa à democracia, sugerindo que, no Brasil, observa-se sutil e discreto desrespeito às premissas basilares da democracia constitucional - ao que se denomina "retrocesso constitucional". A partir dessas análises iniciais, será demonstrado, através da discussão da Proposta de Emenda Constitucional no 29/2015, como o retrocesso constitucional se perfaz em termos práticos, utilizando-se, ainda de mecanismos democráticos e constitucionais. Para tanto, ressalta-se o modo pelo qual os parlamentares democraticamente eleitos fazem uso da Emenda Constitucional para marginalizar as minorias - no caso em tela, mulheres, as quais têm seus direitos reprodutivos cerceados e, por conseguinte, são excluídas do debate democrático, vez que este tem como premissa a liberdade e igualdade entre os cidadãos. Por fim, conclui-se pela existência de falhas no modelo democrático brasileiro e pela necessidade de sua reformulação, a fim de garantir, por fim, os direitos fundamentais elencados pela Constituição Federal de 1988. Resta evidente, pois, que para mais de apresentar um modelo de democracia constitucional acanhado que, por ora, não se efetivou plenamente em termos práticos, o Brasil vive uma ameaça ao seu regime democrático nos termos desenvolvidos no presente trabalho. Reforça-se, como reação contrária aos referidos acontecimentos, a necessidade de fomento do pluralismo jurídico, com uma população livre para escolher e se manifestar nos debates políticos a fim de, enfim, recuperar qualitativamente o modelo de democracia constitucional brasileiro. Faz-se mister, pois, a promoção de um governo democrático que preze, especialmente, por uma participação igualitária, pela liberdade de expressão e exercício dos direitos humanos. No que toca, especialmente, ao objeto deste trabalho, é indispensável que os governos propiciem os meios à participação das mulheres na vida política, vez que são cidadãs à mesma maneira que os homens e, portanto, nos termos do artigo $1^{\circ}$ da Constituição Federal, são demandadas no processo de tomada de decisões.
\end{abstract}

Palavras-chave: Democracia. Retrocesso constitucional. Direitos reprodutivos. Participação política igualitária. Direitos fundamentais das mulheres.

Artigo recebido em 15 jul. 2019 e aprovado em 23 ago. 2019. 


\begin{abstract}
The purpose of this paper is to discuss democratic theories and their association with constitutionalism, in order to demonstrate how democracy - with a special focus on Brazilian democracy - shows a qualitative decline that occurs exponentially through democratic and constitutional provisions. Firstly, it intends to briefly present the concept of democracy and its necessary association with fundamental rights, only to conclude that the democratic model adopted in Brazil is insufficient to implement in practical terms the promises of the programmatic constitution. In the sequence, it is attempted to demonstrate the ways of offending to the democracy, suggesting that, in Brazil, one observes subtle and discreet disrespect to the basic premises of the constitutional democracy - to what is denominated "constitutional retrocession". From these initial analyzes, it will be demonstrated, through the discussion of Proposed Constitutional Amendment $n^{\circ} 29 / 2015$, how the constitutional retrocession is practical, using democratic and constitutional mechanisms. In order to do so, the way democratically elected parliamentarians make use of this Constitutional Amendment to marginalize minorities - in the present case, women, who have their reproductive rights curtailed and, therefore, are excluded from the democratic debate, as this has as premise the freedom and equality between citizens. Finally, it is concluded that there are flaws in the Brazilian democratic model and the need for its reformulation, in order to guarantee the fundamental rights enshrined in the $\mathrm{Fe}$ deral Constitution of 1988.

It remains evident, therefore, that in order to present a model of limited constitutional democracy that, for the time being, has not been fully implemented in practical terms, Brazil is facing a threat to its democratic regime in the terms developed in the present work. The need to foster legal pluralism, with a population free to choose and manifest itself in political debates, is reinforced as a reaction against these events, in order to qualitatively recover the model of Brazilian constitutional democracy. It is therefore necessary to promote a democratic government that is especially committed to equal participation, freedom of expression and the exercise of human rights. In regards to the object of this work, in particular, , it is indispensable that governments provide the means for the participation of women in political life, since they are citizens in the same way as men and therefore, under the terms of article 1 of the Federal Constitution, are required in the decision-making process.
\end{abstract}

Keywords: Democracy. Constitutional retrocession. Reproductive Rights. Equal Political Participation. Fundamental Rights of Women. 


\section{Introdução}

A história da democracia brasileira é marcada por diferentes períodos de interrupção do regime democrático e autoritarismos, sendo o mais emblemático e memorável deles o período de Ditadura Militar entre os anos de 1964 e 1985, cujos vestígios antidemocráticos e as atrocidades cometidas ecoam até os dias de hoje.

Em vista desse passado composto por inúmeros retrocessos em matéria de direitos, garantias e liberdades individuais, a democracia brasileira, recém reconquistada em 1985, em muito diverge da concepção tradicional dada ao termo, assumindo um compromisso com a garantia de direitos por anos negados à população.

A redemocratização do Estado brasileiro traz consigo uma promessa de igualdade e transformação social, e é exatamente nesse sentido que diverge dos modelos anteriores, "visando à construção de um novo contexto social”. (ALVES; FERNANDES, 2015, p. 24)

Apesar do processo de redemocratização brasileiro ter se consolidado com a eleição do primeiro presidente civil após vinte e um anos de ditadura, a democracia não se limita ao sufrágio.

A democracia, porém, vai muito mais além, tem alcance muito mais amplo e dimensão muito mais profunda; ao mesmo tempo em que se contrapõe aos desmandos autoritários, se insere nos cotidianos interferindo nas muitas formas de exercício de dominação, pondo em xeque as relações de gênero e poder. (FERREIRA, 2015, p. 215).

A despeito de ter como constante o governo do povo, o conceito de democracia não é estável, muito menos imutável, sendo um projeto em constante movimento de construção e desconstrução.

Em que pese a suposta impossibilidade de sucumbência do regime democrático e a simulada indiscutibilidade de seu discurso, a democracia exige continuada atividade a fim de garantir a sua manutenção. O que tem se observado em diversos países, contudo, é uma ação que caminha na contramão dessa proposição. Como apontado por alguns teóricos neste trabalho, a falta de progresso na democracia, sua recessão ou até mesmo os movimentos de retrocesso democrático demonstram que o regime está em evidente recuo. 
O objetivo deste artigo, portanto, é discorrer a respeito das teorias democráticas, bem como sua associação ao constitucionalismo, a fim de demonstrar como a democracia - com especial enfoque na democracia brasileira -, apresenta uma queda qualitativa que se dá, exponencialmente, por meios democráticos e constitucionais. Para tanto, o presente trabalho se subdivide em quatro pontos de desenvolvimento. O ponto 02 (dois), primeiramente, busca apresentar brevemente o conceito de democracia e sua necessária associação com os direitos fundamentais apenas para concluir que o modelo democrático adotado no Brasil é insuficiente para efetivar em termos práticos as promessas da constituição programática. O ponto 03 (três) visa a demonstrar as maneiras de ofensa à democracia, sugerindo que, no Brasil, observa-se sutil e discreto desrespeito às premissas basilares da democracia constitucional - ao que se denomina "retrocesso constitucional". O ponto 04 (quatro), por sua vez, visa demonstrar, através da discussão da Proposta de Emenda Constitucional no 29/2015, como o retrocesso constitucional se perfaz em termos práticos, utilizando-se, ainda, de mecanismos democráticos e constitucionais. Para tanto, tal qual exposto, ressalta de que modo parlamentares democraticamente eleitos fazem uso da Emenda Constitucional para marginalizar as minorias - no caso em tela, mulheres, as quais têm seus direitos reprodutivos cerceados e, por conseguinte, são excluídas do debate democrático, vez que este tem como premissa a liberdade e igualdade entre os cidadãos. Por fim, o artigo conclui as falhas no modelo democrático brasileiro e demanda a necessidade de sua reformulação, para garantir, por fim, os direitos fundamentais elencados pela Constituição Federal de 1988.

\section{Democracia e constitucionalismo: falhas na concretização do regime democrático brasileiro}

Aprioristicamente, é comum que a análise da democracia se dê sob o ponto de vista procedimental. O que se pretende no presente trabalho, todavia, é uma compreensão do conceito para além de seu aspecto formal, compreendendo-o como atrelado à garantia e ao exercício de direitos fundamentais que configurariam, por sua vez, condições essenciais à própria existência da democracia.

Nas palavras de Norberto Bobbio, a democracia pressupõe o respeito a determinados direitos básicos para que até mesmo seus mecanismos mais procedimentais funcionem corretamente, de forma que "as normas 
constitucionais que atribuem esses direitos não são exatamente regras do jogo: são regras preliminares que permitem o desenrolar do jogo" (BOBBIO, 1986, p. 32).

O voto majoritário é, sim, de suma importância em uma democracia, figurando como "pedra fundamental da democracia representativa" (BARBOZA, 2005, p. 19). Porém, como colocado por Estefânia Maria de Queiroz Barboza, "o mesmo não é suficiente para garantir decisões corretas ou mesmo resultados justos ou racionais, uma vez que o princípio majoritário não assegura igualdade política” (BARBOZA, 2005, p. 19).

O aprofundamento da democracia depende da garantia de acesso ao poder político a todos os segmentos sociais, isto é, depende da existência de condições efetivas que assegurem a participação e/ou influência de todos membros adultos da comunidade política no processo de tomada de decisões que os afetam. (MOISÉS; SANCHEZ, p. 93)

A implementação de eleições livres, universais e regulares não se mostra suficiente para que automaticamente seja caracterizada uma democracia. Como defendido por José Álvaro Moisés e Beatriz Rodrigues Sanchez, o regime democrático tem sido classificado pela literatura como um "fenômeno de natureza multidimensional que envolve eleições, direitos fundamentais, instituições de intermediação de interesses e a cultura cívica dos cidadãos” (MOISÉS; SANCHEZ, p. 95). Da mesma maneira argumenta Kim Lane Scheppele ao afirmar que "democracia associada ao constitucionalismo reforça as ideias de que ao estado cabe proteger e defender a dignidade e a liberdade dos indivíduos para que eles sustentem, entre outras coisas, a capacidade de serem cidadãos democráticos” (SCHEPELLE, p. 558).

Importante apontar, conforme criticado pelos autores supracitados, que, apesar da expansão das teorias democráticas e do surgimento de definições mais substanciais sobre o conceito, de modo geral foram deixados "fora do debate o tratamento desigual dado às mulheres e outros outsiders nesse processo" (MOISÉS; SANCHEZ, p. 95).

Dessa forma, na concepção de Moisés e Sanchez, a melhor maneira de análise da democracia seria aquela que a define em termos de sua qualidade, na qual "os conteúdos do regime democrático, isto é, os princípios de liberdade e igualdade, assim como a exigência de sua articulação, têm lugar central” (MOISÉS; SANCHEZ, p. 97): 
No caso da democracia, espera-se que ela seja capaz de satisfazer as expectativas dos cidadãos quanto à missão que eles atribuem aos governos (qualidade de resultados); à garantia de seus direitos de liberdade e de igualdade políticas necessárias para participar e alcançar seus interesses e preferências (qualidade de conteúdo); e à existência de métodos ou procedimentos institucionais de escolha de governantes e de sua responsabilização destinados a capacitar os cidadãos a avaliar e julgar o desempenho de governos e de representantes autorizados a agir em seu nome. (MOISÉS; SANCHEZ, p. 97)

A Constituição de 1988, além de representar um "marco jurídico na transição democrática” (PIOVESAN, p. 1), elenca um amplo rol de direitos e garantias fundamentais, pautando-se na igualdade sem distinções de qualquer natureza, a fim de garantir a todos e todas a plena participação democrática. Sob essa ótica, e da análise da unidade da Constituição, o que se verifica é que a Carta Constitucional deixa clara não somente a adoção do modelo democrático, mas da democracia constitucional, isto é, os representantes democraticamente eleitos têm seu poder limitado pelos direitos e garantias fundamentais estabelecidos na Constituição, principalmente aqueles que dizem respeito ao princípio da igualdade e à proteção das liberdades individuais.

E são esses direitos e garantias fundamentais constitucionalmente protegidos que asseguram o próprio processo democrático, como destaca Cláudio Ari Mello.

(...) os direitos fundamentais são pré-comprometimentos escolhidos pela própria soberania popular, no exercício do poder constituinte originário, e convertidos em direitos constitucionais atribuídos aos indivíduos, inclusive - e sobretudo - em face dos próprios órgãos governamentais criados pelo poder constituinte originário. (MELLO, 2004, p. 144)

Nesse diapasão, imperioso destacar que a democracia pretendida na Constituição de 1988 também não se pauta somente na vontade da maioria, mas compromete-se com os direitos das minorias, impedindo que as decisões se limitem à vontade de maiorias políticas eventuais e que os grupos minoritários sejam silenciados no debate público democrático. 
O princípio democrático, regido precipuamente, como bem demonstraram Zuq e Ginsburg (GINSBURG, 2018), pela manutenção de eleições livres, é encontrado no caput do artigo $1^{\circ}$ da Constituição Federal de 1988. É a democracia, pois, que consagra a maneira de se garantir o melhor à sociedade e, para tanto, exige a participação de todos e todas na vida política do país - especialmente no que toca à efetivação dos objetivos fundamentais da República. Ademais, como se observa no artigo 5, XXII da Carta Magna, a referida democracia deve ser permeada pelo Princípio da Justiça Social, entendendo-se como tal "o que confere o direito à sociedade de exigir do estado um atuação vinculada à redução dos desequilíbrios sociais e comprometida simultaneamente com a garantia e promoção da igualdade de todos os seus integrantes (...)” (ALVES; FERNANDES, 2015, p. 27).

Em que pese a aspiração constitucional de garantir uma sociedade livre, justa e solidária, tal propósito resvala diante da dificuldade de concretização. É perante referido impedimento que se deve buscar uma revisão da Constituição, e não simples desconsideração de seus preceitos. Nas palavras de Alinne Cardim Alves e Cassiane de Melo Fernandes:

Completando sua afirmação, de que os inconvenientes se devam resolver, são no caso de déficit de concretização dos direitos sociais, pelo apuramento da realização constitucional, pelo amadurecimento da sociedade e de suas instituições, não pela busca de solução que parece mais simples (...) (ALVES; FERNANDES, 2015, p. 27)

É indispensável ao Estado brasileiro, portanto, adotar um modelo de democracia que condiga com suas peculiaridades, a fim de concretizar, pelas vias do debate público, o que antes previa a Constituição programática.

Segundo Bobbio, para que se realize efetivamente o debate público, à maneira que propõem Alves e Fernandes, "é necessário que aos chamados a decidir sejam garantidos os assim denominados direitos de liberdade, de opinião, de expressão das próprias opiniões, de reunião, associação, etc. (...)" (BOBBIO, 1986, p. 27). Estes, para além de meros direitos fundamentais de primeira geração, são os pressupostos necessários ao funcionamento dos mecanismos procedimentais que caracterizam um regime democrático. Além das regras do jogo democrático sugeridas por Bobbio, Alves e Fernandes reforçam que é fundamental à democracia o fato de que "são os cidadãos livres e iguais que constroem os termos políticos que regulam sua cooperação social (BOBBIO, 1986, p. 29)". 


\section{Reversão autoritária e retrocesso constitucional}

A história republicana do Brasil, como sugere o professor Caio Navarro de Toledo, é marcada por eminente ameaça às instituições políticas do país - especialmente no que toca aos governos democráticos dos anos 40 aos 60. Em abril de 1964, finalmente, deu-se lugar ao golpe militar, fortemente reivindicado pela sociedade civil do período. Para além de estancar a multiplicidade de debates políticos e ideológicos existentes à época, o golpe visou, principalmente, conter a democracia e as incessantes demandas por ampliação de cidadania dos trabalhadores. Ademais de um sindicalismo cada vez mais presente, o momento foi marcado por luta pela reforma agrária, resistência dos trabalhadores do campo e, ao que concerne ao tema deste trabalho, reivindicações políticas em prol da expansão democrática. Nas palavras de Caio Navarro de Toledo:

No pré-64, outras reivindicações políticas visavam ao alargamento da democracia liberal vigente no país: entre elas, o direito de voto aos analfabetos, o direito dos setores subalternos das forças armadas de postulares cargos eletivos e a legalidade do Partido Comunista Brasileiro, posto fora da lei desde 1947. (TOLEDO, 2004)

Consoante dissertam os professores Aziz Huq e Tom Ginsburg, o golpe militar de 1964 e a consequente ruptura do regime democrático da época são denominados reversão autoritária. Trata-se, pois, de "uma mudança súbita do regime democrático para o regime autoritário, normalmente associada a golpes militares e estados de emergência" (GINSBURG; HUQ, 2018).

As erosões de regimes democráticos, contudo, nem sempre versam sobre momentos abruptos, repentinos e completos. Como apresenta Kim Lane Scheppele, entre os anos de 2006 e 2016, mais países apresentaram quedas no que toca à qualidade de sua democracia, ao invés de melhorias. Por vezes, em suma, a democracia liberal constitucional sofre um regresso qualitativo muito mais lento e imperceptível, o qual demanda da doutrina, portanto, conceito diverso: o retrocesso constitucional.

Uma democracia constitucional e liberal, em que pese não entrar em colapso, pode se sujeitar à degradação de maneira sutil. Segundo sugerem Aziz Huq e Tom Ginsburg, tal transformação acontece quando suce- 
dem, simultaneamente, ataques aos três pilares da democracia clássica. Nas palavras dos autores:

A democracia é constantemente reduzida ao fundamento aparentemente simples das eleições competitivas. (...). Demanda-se, ainda, três pilares que enrobustecem o conceito: a) um sistema eleitoral democrático, período, livre e justo, no qual o perdedor cede o poder; b) o direito de expressão e associação; c) a estabilidade, previsibilidade e integridade das leis e instituições democráticas. Cabe ressaltar, neste ponto, que os conceitos não se confundem; apenas se fortalecem mutuamente. (SCHEPPELE, p. 03)

Na Hungria, a título de exemplo, o governo democraticamente eleito buscou a promulgação de leis e mudanças institucionais que, simultaneamente, visaram ao fim da competição eleitoral, dos direitos liberais e da participação democrática, para além de agredir a estabilidade de previsibilidade do Direito. Toma-se como amostra, ainda, o cenário da Venezuela entre os anos de 1999 e 2013. O regime estabelecido por Hugo Chávez engrandeceu o poder executivo, limitou a oposição política, atacou a academia e sufocou a mídia da mesma maneira dos regimes autoritários clássicos. Ressalta-se que, a despeito das possíveis distinções observadas entre as tantas mudanças realizadas pelos respectivos governos, todas as medidas são salvaguardadas pela aparente legalidade que as reveste.

Dado que se trata de um fenômeno sutil, o retrocesso constitucional demanda a verificação de mudanças diversas e qualificadas nos regimes legais e instituições democráticas a fim de se constatar, de fato, sua ocorrência. Referidas alterações podem ser inócuas ou, em um primeiro momento, defensáveis - em especial quando avaliadas individualmente. É somente através da cumulação e da interação das mudanças que se percebe o efeito do retrocesso. A despeito de quais diligências conduzem a tal acontecimento, seu ponto final é um regime híbrido que não se assemelha à democracia e tampouco condiz com regimes autoritários clássicos - não obstante incluir elementos de ambos.

O retrocesso constitucional, em síntese, é compreendido como um substituto parcial do autoritarismo. Em que pese seu grau de concentração ou, ainda, de imunidade do controle democrático, ser menor do que aquele oriundo de um golpe, observa-se que também é um caminho mais atraente, vez que incita menos resistência. Graças a essa dinâmica imper- 
ceptível, é evidente e pouco surpreendente o elevado número de países que sofreram com a queda de qualidade de sua democracia, em vez de experimentarem um colapso total do regime.

Scheppele, ao seu turno, acresceu ao debate apresentando, ademais de seu próprio conceito, o cenário em torno do fenômeno do retrocesso constitucional. Dentre as causas da erosão democrática, de acordo com a autora, está a desilusão dos cidadãos com o funcionamento do regime - de tal sorte que estes consideram alternativas à democracia constitucional liberal. De outra banda, simultaneamente ao mencionado descontentamento, a comunidade internacional buscou o desenvolvimento de instituições e normas que deveriam respaldar toda a democracia liberal e constitucional ao redor do globo. A despeito de referida normatização, ainda é crescente o número de governos que se distanciam do que fora estabelecido pela transnational legal order e se aproximam do retrocesso constitucional - ou, como coloca Scheppele, das democratorships. Nas palavras da autora, "democratorships estão, como o termo sugere, suspensas entre a democracia e a ditadura, com características de ambos (SCHEPPELE, p. 04). "

Além de ferir os pilares da democracia clássica, como outrora sugeriram Huq e Ginsburg, as democratorships têm como marca principal se revestirem de legitimidade constitucional justamente para ferir preceitos inerentes ao constitucionalismo, tais quais a limitação legal do poder público, o exercício do poder de maneira transparente e, no que toca ao tema do trabalho em tela, a incondicional proteção dos direitos. Os Estados que apresentam retrocesso constitucional, portanto, agem de forma a aparentar legalidade e coerência com o constitucionalismo ainda que, em verdade, estejam ruindo sua manutenção por meio da concentração do poder de forma imponderada nas mãos de poucos líderes.

Posto o conceito do retrocesso constitucional e suas consequências ao regime democrático constitucional, é imperioso discorrer a respeito de sua aparente ocorrência no Estado Democrático de Direito brasileiro.

\section{A erosão constitucional brasileira à luz da Proposta de Emenda Constitucional no ${ }^{-29 / 2015}$}

Se há imperfeição relativa à concretização da democracia brasileira - como já se demonstrou no primeiro ponto do presente trabalho -, é evidente que tal deficiência reverbera na efetivação de direitos fundamentais, 
vez que estes se apresentam como resultado da luta política. Como explica o ministro Marco Aurélio de Mello, citado por Alinne Cardim Alves e Cassiane de Melo Fernandes, a restrição dos direitos fundamentais se percebe, especialmente, nos grupos minoritários. São tolhidas, principalmente, “(...) a liberdade de se expressar, de se organizar, de discordar e de se fazer representar nas decisões que influenciem nos destinados da sociedade como um todo (...)" (MELLO, p. 28).

Em que pese não se tratar de minoria numérica no território brasileiro, as mulheres ainda seguem com apenas 10,5\% de representação no Congresso, colocando o país na $152^{\circ}$ posição no ranking de representatividade feminina na Câmara dos Deputados (PAINS, 2018). Trata-se, portanto, de uma parcela da população que, como sugere Marco Aurélio de Mello, tem seus direitos fundamentais restringidos em função da parca modalidade democrática do país. Vide, a título de exemplo, a Proposta de Emenda à Constituição n⿳2 29, de 2015, de autoria dos Senadores Magno Malta (PR/ ES), Aécio Neves (PSDB/MG), entre outros parlamentares ${ }^{1}$. Propõem os autores que, no caput do artigo $5^{\circ}$ da Constituição Federal, passarão a constar os vocábulos "desde a concepção" no que concerne à inviolabilidade do direito à vida sob o argumento de "grave atentado à dignidade da pessoa humana que se vê privada de proteção jurídica na fase da gestação."

Considerando que a proposta de Emenda Constitucional se trata de evidente inobservância dos direitos sexuais e reprodutivos das mulheres - em manifesta contrariedade em relação às manifestações mundiais sobre o direito ao aborto -, a PEC 29/2015 é notoriamente antidemocrática, vez que visa impossibilitar o direito fundamental à liberdade e à igualdade direitos esses que, como apresentados anteriormente, são fundamentais à manutenção das regras do jogo democrático. Diz Flávia Biroli:

O direito ao aborto é um eixo central da autonomia das mulheres. Sem o direito de controlar sua capacidade reprodutiva, a autonomia na definição de sua trajetória de vida fica fundamentalmente comprometida. (...) Falar de aborto nos leva a tocar em questões fundamentais para a cidadania e a democracia. Não se trata de um problema das mulheres, mas de um problema das sociedades de-

\footnotetext{
${ }^{1}$ Emenda Constitucional no 29, de 19 de março de 2015. Altera a Constituição Federal para acrescentar no art. $5^{\circ}$, a explicação inequívoca "da inviolabilidade do direito à vida, desde a concepção. Disponível em: <https://legis.senado.leg.br/sdleg-getter/documento?d$\mathrm{m}=3455035 \&$ ts $=1556136400928 \&$ disposition=inline $>$. Acesso em: 29 abr. 2019 .
} 
mocráticas e de como impedem ou possibilitam aos indivíduos do sexo feminino o controle sobre o que se passa no e com seu próprio corpo. (BIROLI, 2018, p. 135 e 146)

Atente-se que, em um primeiro momento, em que pese a manifesta característica antidemocrática da PEC nº 29/2015, não há abrupta ruptura do regime democrático tal qual houvera com o golpe militar em 1964. O regime foi, em verdade, reproposto por parlamentares democraticamente eleitos. Não há estado de emergência, tampouco violação dos direitos da maioria. Há meramente um enfraquecimento da minoria, revestido de legalidade e democracia.

Logicamente, o fato de não haver tanques nas ruas nem massiva agressão aos direitos humanos é sinal de progresso e sucesso dos sistemas internacionais. Contudo, os Estados marcados pela erosão democrática, como é o caso do Brasil, encontraram outras maneiras de marginalizar oposições e minorias claramente coercitivas, mas formalmente constitucionais:

Os novos autocratas aprenderam que eles podem se consolidar no poder se eles puderem simplesmente fazer com que seus oponentes desistam e vão embora, ou fiquem em casa e 'cuidem de suas vidas'. Eles não precisam aprisioná-los ou matá-los; eles simplesmente precisam fazê-los tolerar a diminuta liberdade oferecida. (SCHEPELLE, p. 578)

Apesar da aparente constitucionalidade e de se auto declararem democraticamente eleitos, em suma, há evidente desrespeito às premissas basilares do constitucionalismo, posto que não há respeito ou tolerância às minorias e ao pluralismo, tampouco há a crença de que o poder público deve ter comprometimento com os princípios constitucionais.

\section{Considerações finais}

Diante do cenário brasileiro, é preciso retomar e delongar os conceitos que inauguraram a reflexão desenvolvida no presente trabalho.

A democracia e o constitucionalismo, como se observa rotineiramente na política brasileira, estão em constante atrito, especialmente quando há divergência entre os princípios constitucionais e as demandas dos cidadãos. Isso porque os conceitos são, aprioristicamente, inconciliáveis. Nas palavras de Kim Lane Scheppele: 
Democracia é um sistema político no qual líderes são responsáveis pelo povo; constitucionalismo é um sistema político no qual tanto os líderes como o povo estão comprometidos com um sistema constitucional voltado à garantia de princípios básicos que transcendem o momento de demanda. Democracia e constitucionalismo podem entrar em conflito quando o povo falha em sua obrigação constitucional e as eleições produzem uma maioria para mudanças inconstitucionais. Ou a tensão entre constitucionalismo e democracia pode criar uma crise na qual a elite oferece ao povo escolhas que findam o liberalismo. (SCHEPPELE, p. 557)

A tensão sugerida por Kim Lane Scheppele resulta, pois, em um "majoritarismo" que mina os direitos fundamentais outrora garantidos pelo constitucionalismo. Como bem se demonstrou no trabalho em tela, parlamentares e líderes eleitos democraticamente estão cientes das decorrências desse atrito. Assim sendo, buscam utilizar uma simples equivalência entre democracia e maioria para enfrentar as medidas constitucionais que constringem as vontades do eleitorado. Essa medida, ente outras tantas, tal e qual exposto, leva ao que se denomina erosão constitucional, democratorship ou retrocesso constitucional.

O retrocesso constitucional apresentado por Huq e Ginsburg versa, novamente, sobre sucessivos ataques aos principais predicados da democracia: a qualidade das eleições, os direitos de expressão e associação, e as normativas legais. Adiciona-se ao conceito, ainda, a compreensão de Scheppele, a qual ressalta que a democracia tem como inexorável conteúdo a proteção de direitos fundamentais, oriunda do constitucionalismo.

Relembram os autores, outrossim, que "o uso de formas constitucionais e democráticas para atingir fins antidemocráticos não é nada novo." Vide, a título de exemplo, o uso de emenda constitucional a fim de proporcionar a erosão democrática, fazendo daquela uma ferramenta para evitar a atividade deliberativa outrora sugerida neste trabalho:

"O primeiro e talvez mais evidente caminho para a erosão democrática envolve o uso da emenda constitucional como ferramenta para marginalizar a oposição política e o pluralismo deliberativo. A emenda de um texto constitucional pode ter como alvo estruturas democráticas ou direitos liberais (...)" (SCHEPPELE, p. 137) 
À mesma maneira argumenta Scheppele. Para além de ser preocupante o número de países que se distanciaram do modelo democrático, o que é de fato alarmante não são as razões para tal fenômeno, mas o modo como ele acontece. "Algumas democracias constitucionais são deliberadamente sucumbidas por uma série de leis autocráticas que usam do constitucionalismo e da democracia para destruí-los. (SCHEPPELE, p. 547) ". A Emenda Constitucional, portanto, é instrumento bastante efetivo para atingir estruturas institucionais ou, como se observa na Proposta de Emenda Constitucional $n^{\underline{0}}$ 29/2015, tolher direitos fundamentais.

Resta evidente, pois, que, para mais de apresentar um modelo de democracia constitucional acanhado que, por ora, não se efetivou plenamente em termos práticos, o Brasil vive uma ameaça ao seu regime democrático nos termos desenvolvidos no presente trabalho. Reforça-se, como reação contrária aos referidos acontecimentos, a necessidade de fomento do pluralismo jurídico, com uma população livre para escolher e se manifestar nos debates políticos, visando, enfim, recuperar qualitativamente o modelo de democracia constitucional brasileiro. Faz-se mister, pois, a promoção de um governo democrático que preze, especialmente, por uma participação igualitária, pela liberdade de expressão e exercício dos direitos humanos. No que toca, especialmente, ao objeto deste artigo, é indispensável que os governos propiciem os meios à participação das mulheres na vida política, vez que são cidadãs à mesma maneira que os homens e, portanto, nos termos do artigo $1^{\varrho}$ da Constituição Federal, são demandadas no processo de tomada de decisões. Dizem Alves e Fernandes: "democracia e práticas governativas democráticas, particularmente, significam que os direitos humanos e as liberdades das pessoas são respeitadas, promovidas e cumpridas de forma que estas possam viver com dignidade."

\section{Referências}

ALVES, Alinne Cardim; FERNANDES, Cassiane de Melo. Reconstruindo e reformulando a democracia. In: AMARAL, Sérgio Tibiriçá; SIQUEIRA, Dirceu Pereira (Orgs.) Democracia, liberdade e justiça social: fundamentos para uma teoria jurídica do reconhecimento. São Paulo: Boreal Editora, 2015. 
BARBOZA, Estefânia Maria de Queiroz. A legitimidade democrática da jurisdição constitucional na realização dos direitos fundamentais sociais. 185 f. Dissertação (Mestrado) - Curso de Direito, Pontifícia Universidade Católica do Paraná, Curitiba, 2005.

BIROLI, Flávia. Gênero e desigualdades: limites da democracia no Brasil. São Paulo: Boitempo, 2018.

BOBBIO, Norberto. O futuro da democracia: uma defesa das regras do jogo. 6. ed. Rio de Janeiro: Paz e Terra. 1986.

BRASIL. Constituição (1988). Emenda Constitucional n² 29, de 19 de março de 2015. Altera a Constituição Federal para acrescentar no art. 5º, a explicação inequívoca "da inviolabilidade do direito à vida, desde a concepção. Disponível em: < https://legis.senado.leg.br/sdleg-getter/documento?dm=3455035\&t$\mathrm{s}=1556136400928 \&$ disposition=inline $>$ Acesso em 30 abr. 2019.

BRASIL. Constituição da República Federativa do Brasil. Promulgada em 5 de outubro de 1988. Brasília, DF. Disponível em < http://www.planalto.gov. br/ccivil_03/constituicao/constituicao.htm> Acesso em 30 abr. 2019.

FERREIRA, Maria Mary. Igualdade de gênero e participação política: As contradições do Estado brasileiro. In: SOUZA, Cristiane Aquino de (Org.). Democracia, Igualdade e Liberdade: Perspectivas Jurídicas e Filosóficas. Rio de Janeiro: Lumen Juris, 2015, p. 211-228.

GINSBURG, Tom; HUQ, Aziz. How to Lose a Constitucional Democracy. U.C.L.A Law Review 78. 2018. Disponível em < https://www. uclalawreview.org/wp-content/uploads/securepdfs/2018/03/Huq-Ginsburg-65-1.pdf> Acesso em 30 abr. 2019.

MELLO, Cláudio Ari. Democracia Constitucional e Direitos Fundamentais. Porto Alegre: Livraria do Advogado, 2004.

MOISÉS, José Álvaro; SANCHEZ, Beatriz Rodrigues. Representação Política das Mulheres e Qualidade da Democracia: O caso do Brasil. p. 93. Disponível em < https://www.academia.edu/9263393/Representa\%oC3\%A7\%C3\%A3o_pol\%C3\%ADtica_das_mulheres_e_qualidade_da_democracia_o_caso_do_Brasil> Acesso em 30 abr. 2019.

PAINS, Clarissa. Brasil tem menos parlamentares mulheres do que 151 países. O Globo. 07 mar. 2018. Disponível em < https://oglobo.globo. $\mathrm{com} /$ sociedade/brasil-tem-menos-parlamentares-mulheres-do-que-151-paises-22462336> Acesso em 30 abr. 2019 
SCHEPELLE, Kim Lane. Autocratic Legalism. p. 547. Disponível em < https://lawreview.uchicago.edu/sites/lawreview.uchicago.edu/files/11\%20 Scheppele_SYMP_Online.pdf> Acesso em 30 abr. 2019.

Worst practices and the transnational legal ordem (or how to build a constitutional "democratorship" in plain sight). Disponível em: $<$ https://www.law.utoronto.ca/utfl_file/count/documents/events/wright-scheppele2016.pdf?fbclid=IwAR1rUPFoWsdS1FqzgEEL1FpM_04As-FgiMCXMYtF_1JO4ahAKuDnfIUPLNs>

TOLEDO, Caio Navarro. 1964: O golpe contra as reformas e a democracia. Revista Brasileira de História. Vol. 24. N. 47. São Paulo. 2004. Disponível em <http:/ /www.scielo.br/scielo.php?script=sci_arttext\&pi$\mathrm{d}=$ S0102-01882004000100002> Acesso em 30 abr. 2019.

Júlia Carolina Costa Lima - Bacharela em Direito pela Universidade Federal do Paraná. Pós-graduanda em Direito Penal e Direito Processual Penal pela Academia Brasileira de Direito Constitucional.

Marina Bonatto - Bacharela em Direito pela Universidade Federal do Paraná. Mestranda em Direito da Pontifícia Universidade Católica do Paraná. Advogada devidamente inscrita na Ordem dos Advogados do Brasil, seção Paraná. 